\title{
Tracheobronchoplasty followed by bilateral lung transplantation for Mounier-Kuhn syndrome
}

Ben Dunne, MD, Philippe Lemaître, MD, Marc de Perrot, MD, Cecilia Chaparro, MD, and

Shaf Keshavjee, MD, Toronto, Ontario, Canada

From the Toronto Lung Transplant Program, Toronto General Hospital, University Health Network, University of Toronto, Toronto, Ontario, Canada.

Disclosures: The authors reported no conflicts of interest

The Journal policy requires editors and reviewers to disclose conflicts of interest and to decline handling or reviewing manuscripts for which they may have a conflict of interest. The editors and reviewers of this article have no conflicts of interest.

Received for publication March 28, 2020; revisions received March 28, 2020; accepted for publication April 2, 2020; available ahead of print April 11, 2020.

Address for reprints: Shaf Keshavjee, MD, Toronto Lung Transplant Program, Toronto General Hospital, 200 Elizabeth St, 9N-946, Toronto, Ontario, M5G 2C4 Canada (E-mail: shaf.keshavjee@uhn.ca).

JTCVS Techniques 2020;3:400-2

2666-2507

Copyright (C 2020 The Authors. Published by Elsevier Inc. on behalf of The American Association for Thoracic Surgery. This is an open access article under the CC BY-NC-ND license (http://creativecommons.org/licenses/bync-nd/4.0/).

https://doi.org/10.1016/j.xjtc.2020.04.003

Mounier-Kuhn syndrome (MKS), also known as idiopathic tracheobronchomegaly, is a rare cause of tracheobronchomalacia. ${ }^{1}$ We present a case of a patient who required surgical treatment of his large airways disease followed some years later by bilateral lung transplantation for parenchymal disease. The clinical decision making related to performing a Marlex (Bard, Murray Hill, NJ) mesh tracheobronchoplasty in a patient likely to require lung transplantation and the technical challenge of bronchial anastomoses after tracheobronchoplasty is described.

\section{CLINICAL CASE}

A male patient was diagnosed with MKS in 1999 at age of 43 years, following investigation for shortness of breath. Over time, these symptoms worsened and he deteriorated due to recurrent lower respiratory tract infections (LRTI). He was found to have mild emphysema/bronchiectasis; however, bronchoscopy demonstrated severe obstructive tracheomalacia. After careful consideration of the potential influence this may have on future transplant candidacy, he underwent a successful tracheobronchoplasty in April 2014 using a Marlex mesh to stabilize the posterior wall of the trachea from the thoracic inlet down to the first bifurcation of both main bronchi.

Bronchoscopy performed 4 months after repair demonstrated excellent stabilization of his airways (Figure 1, A and $B$ ). Clinically, the procedure provided significant symptom relief from his cough and dyspnea although no change was noted in his forced expiratory volume in 1 second, which remained at $1.5 \mathrm{~L}$. However, these benefits continued to be hampered by persisting recurrent LRTI. After 4 years, he had returned to his preoperative condition. His forced expiratory volume in 1 second and diffusing capacity for

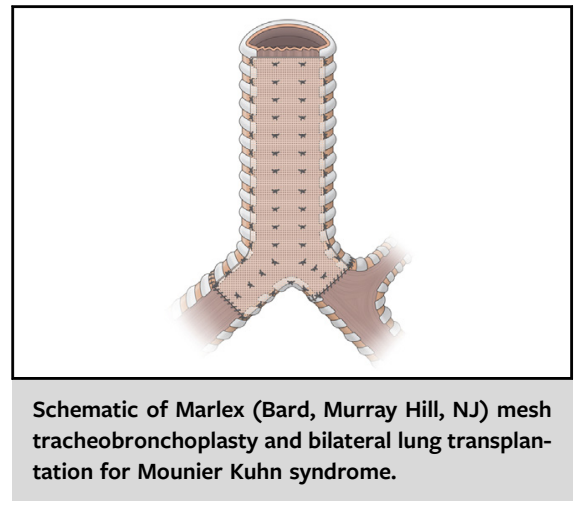

CENTRAL MESSAGE

Successful bilateral lung transplantation can be performed after tracheobronchoplasty with good perioperative outcomes and intermediate-term results.

See Commentaries on pages 403 and 404

carbon monoxide had both deteriorated (from $1.5 \mathrm{~L}$ to $1.2 \mathrm{~L}$ and from $80 \%$ to $48 \%$ predicted, respectively) and his quality of life was poor. There was no evidence of recurrent tracheomalacia on dynamic computed tomography, and combined with clear progression of his parenchymal disease on computed tomography and his worsening diffusing capacity for carbon monoxide, we believed that his deterioration was due to combined bronchiectasis and emphysema, and he underwent bilateral lung transplantation during July 2018.

At time of transplant, a flexible bronchoscopy revealed 2 areas of mesh visible in the distal trachea where it had eroded through. The areas of erosion were in the distal third of the trachea and the right main bronchus (Figure 1,C). The left bronchus was intact. The bronchial dissection was carried out in the standard fashion. The mesh was dissected free from the main bronchi and resected back to the level planned for the anastomoses. The right-sided implant required resection of the portion of the bronchus where the erosion had occurred and performance of the anastomosis very close to the carina. No effort was made to separate the mesh from the posterior membranous airway 


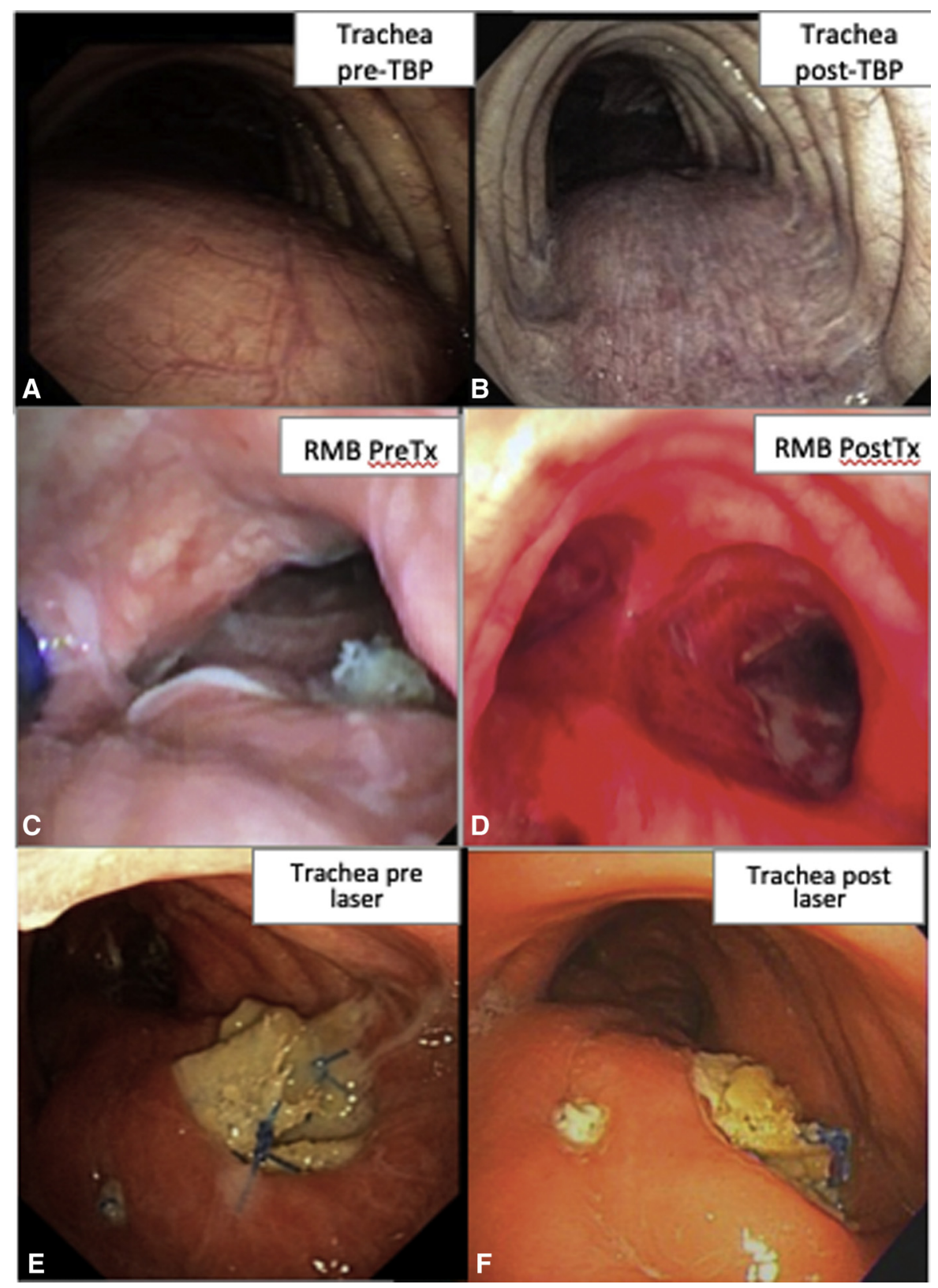

FIGURE 1. A, Trachea before tracheobronchoplasty $(T B P)$. B, Trachea after TBP. C, Mesh in right main bronchus $(R M B)$ and trachea. D, Right main bronchus after transplant $(T x)$. E, Mesh eroding into trachea before laser therapy. F, Mesh in trachea after laser therapy.

because this could have resulted in significant injury. Instead, the donor membranous bronchus was sutured to the recipient posterior wall that was a combination of healed mesh/native membranous airway. As expected with the bronchomegaly of MKS, there was significant size mismatch bilaterally requiring a beveled donor bronchus and telescoping of the donor bronchus into the recipient (Figure 1,D). With the exception of these technical challenges the procedure was straightforward (Figure 2). The patient was extubated on the first postoperative day and his in-hospital recovery was uneventful. He was discharged home after 2 weeks.

Five months posttransplant the portion of mesh eroding into the proximal trachea was debulked with laser via flexible bronchoscopy with good result (Figure 1, $E$ and $F$ ). The intention is to reduce the bulk of the protruding mesh, with repeated laser treatments over time, and allow for the airway to granulate over the mesh. He remains well with excellent lung function at 1-year posttransplant. The informed consent requirement for the publication of the 


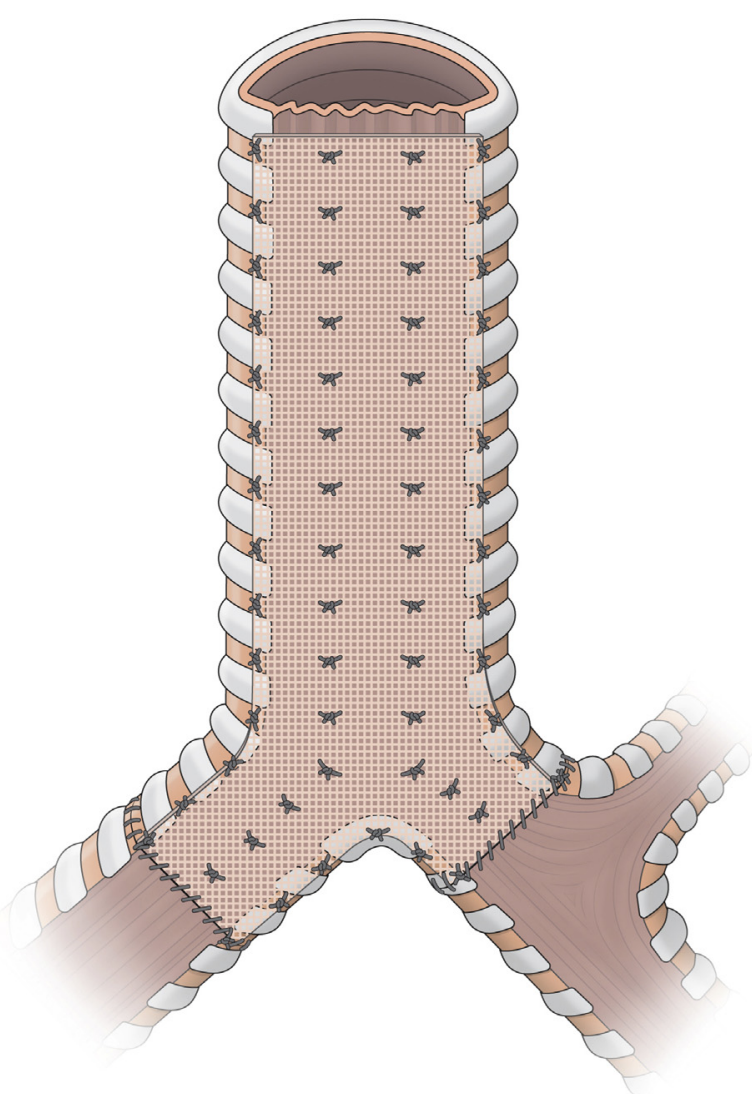

FIGURE 2. Schematic of Marlex (Bard, Murray Hill, NJ) mesh tracheobronchoplasty and bilateral lung transplantation for Mounier-Kuhn syndrome.

study data was waived because there are no identifying features of the patient in this report.

\section{DISCUSSION}

MKS is increasingly recognized and reported. ${ }^{1}$ It is characterized by lack of tone, loss of longitudinal elastic fibers, and thinning of the muscularis mucosae in the membranous portion of the trachea and bronchi. ${ }^{2}$ This causes malacia and dilation of the trachea and proximal bronchi, with transition to a normal caliber and rigidity in more distal lobar and segmental airways. The malacia leads to an inability to clear secretions and a high rate of bronchiectasis $(88 \%)$, tracheal diverticulae $(53 \%)$, and emphysema $(55 \%) .{ }^{3}$ Patients usually present in adulthood with recurrent LRTI, shortness of breath, and chronic cough. Chest radiography or tomography allows diagnosis of tracheomegaly. Flexible bronchoscopy then confirms enlargement at rest and expiratory obstruction. ${ }^{3}$ Dynamic compute tomography can also be used as a diagnostic adjunct although awake bronchoscopy is the diagnostic gold standard.

Intervention is considered in a symptomatic patient with moderate-severe obstruction on bronchoscopy. ${ }^{4}$
The first intervention can be a stenting trial to assess improvement if the contribution of the tracheomalacia to symptoms is unclear. If symptoms improve or if the diagnosis is clear, surgically fit patients with redundant posterior membranous wall can be considered for tracheobronchoplasty.

Tracheobronchoplasty is performed by securing a polypropylene mesh to the posterior aspect of the membranous airway with interrupted sutures. This usually provides airway stabilization and symptom relief.,

Lung transplantation has been performed in MKS patients previously ${ }^{6-8}$; however, the treatment with tracheobronchoplasty and the technical challenges of lung transplantation in a patient following tracheobronchoplasty have not previously been described.

Erosion of the Marlex mesh through the posterior wall of the trachea is an unusual but recognized complication of tracheobronchoplasty. ${ }^{9,10}$ The etiology of this complication is unclear but may be related to excessive tension on the mesh due to overly aggressive reduction in lateral diameter of the dilated airways although the post-tracheobronchoplasty bronchoscopic images in our patient did not show evidence of this. Although it caused no symptoms in our patient, it is a potential source of infection due to chronic colonization. Furthermore, it likely needs to be kept under surveillance in case the degree of erosion worsens or significant granulation tissue develops.

\section{References}

1. Krustins E, Kravale Z, Buls A. Mounier-Kuhn syndrome or congenital tracheobronchomegaly: a literature review. Respir Med. 2013;107:1822-8.

2. Gay S, Dee P. Tracheobronchomegaly — the Mounier-Kuhn syndrome. Br J Radiol. 1984;57:640-4.

3. Schmitt P, Dalar L, Jouneau S, Toublanc B, Camuset J, Chatte G, et al. Respiratory conditions associated with tracheobronchomegaly (MounierKuhn syndrome): a study of seventeen cases. Respiration. 2016;91: 281-7.

4. Odell DD, Shah A, Gangadharan SP, Majid A, Michaud G, Herth F, et al. Airway stenting and tracheobronchoplasty improve respiratory symptoms in MounierKuhn syndrome. Chest. 2011;140:867-73.

5. Gangadharan SP, Bakhos CT, Majid A, Kent MS, Michaud G, Ernst A, et al. Technical aspects and outcomes of tracheobronchoplasty for severe tracheobronchomalacia. Ann Thorac Surg. 2011;91:1574-81.

6. Drain AJ, Perrin F, Tasker A, Stewart S, Wells F, Tsui S, et al. Double lung transplantation in a patient with tracheobronchomegaly (Mounier-Kuhn syndrome). $J$ Heart Lung Transplant. 2006;25:134-6.

7. Minai OA, Mehta AC, Pettersson G, Demet K. Lung transplantation in a patient with Mounier-Kuhn syndrome. J Thorac Cardiovasc Surg. 2006;132: 737-8.

8. Shah SS, Karnak D, Mason D, Murthy S, Pettersson G, Budev M, et al. Pulmonary transplantation in Mounier-Kuhn syndrome: a case report. J Thorac Cardiovasc Surg. 2006;131:757-8.

9. Buitrago DH, Wilson JL, Parikh M, Majid A, Gangadharan SP. Current concepts in severe adult tracheobronchomalacia: evaluation and treatment. J Thorac Dis. 2017;9:E57-66.

10. Wright CD, Mathisen DJ. Tracheobronchoplasty for tracheomalacia. Ann Cardiothorac Surg. 2018;7:261-5. 